\title{
Evidence of prescription of antidepressants for non-psychiatric conditions in primary care: an analysis of guidelines and systematic reviews
}

Alain Mercier ${ }^{1 *}$, Isabelle Auger-Aubin ${ }^{2}$, Jean-Pierre Lebeau ${ }^{3}$, Matthieu Schuers ${ }^{1}$, Pascal Boulet ${ }^{1}$, Jean-Loup Hermil ${ }^{1}$, Paul Van Royen ${ }^{4}$ and Lieve Peremans ${ }^{4,5}$

\begin{abstract}
Background: Antidepressants (ADs) are commonly prescribed in primary care and are mostly indicated for depression. According to the literature, they are now more frequently prescribed for health conditions other than psychiatric ones. Due to their many indications in a wide range of medical fields, assessing the appropriateness of AD prescription seems to be a challenge for GPs. The aim of this study was to review evidence from guidelines for antidepressant prescription for non-psychiatric conditions in Primary Care (PC) settings.
\end{abstract}

Methods: Data were retrieved from French, English and US guideline databases. Guidelines or reviews were eligible if keywords regarding 44 non-psychiatric conditions related to GPs' prescription of ADs were encountered. After excluding psychiatric and non-primary care conditions, the guidelines were checked for keywords related to AD use. The latest updated version of the guidelines was kept. Recent data was searched in the Cochrane Database of Systematic Reviews and in PubMed for updated reviews and randomized control trials (RCTs).

Results: Seventy-eight documents were retrieved and were used to assess the level of evidence of a potential benefit to prescribing an AD. For 15 conditions, there was a consensus that prescribing an AD was beneficial. For 5 others, ADs were seen as potentially beneficial. No proof of benefit was found for 15 conditions and proof of no benefit was found for the last 9. There were higher levels of evidence for pain conditions, (neuropathic pain, diabetic painful neuropathy, central neuropathic pain, migraine, tension-type headaches, and fibromyalgia) incontinence and irritable bowel syndrome. There were difficulties in summarizing the data, due to a lack of information on the level of evidence, and due to variations in efficacy between and among the various classes of ADs.

Conclusions: Prescription of ADs was found to be beneficial for many non-psychiatric health conditions regularly encountered in PC settings. On the whole, the guidelines were heterogeneous, seemingly due to a lack of trials assessing the role of ADs in treatment strategies.

Keywords: Antidepressants, Literature review, Therapeutic use, Family practice

\section{Background}

Antidepressants (ADs) are commonly prescribed in primary care (PC). Among the general population, the 12 month prevalence of ADs consumption ranges from 6\% to nearly $10 \%[1,2]$. The main indications for ADs are major depressive episodes and anxiety. Over the past 20 years, the use of ADs has grown extensively. Most

\footnotetext{
* Correspondence: alain.mercier@univ-rouen.fr

1Department of General Practice, Rouen University and CIC Inserm 0204, University of Rouen, Rouen, France

Full list of author information is available at the end of the article
}

studies have shown a high level of consumption in all industrialised countries. In France, between 1980 and 2008, AD sales increased sevenfold, from $€ 84$ million to $€ 525$ million per year [3]. Selective Serotonin Reuptake Inhibitors (SSRIs) and Selective Norepinephrine Reuptake Inhibitors (SNRIs) accounted for about $80 \%$ of sales. Data in various industrialised countries showed similar results [4-7]. In the United States, ADs are the third most commonly prescribed medication $[8,9]$. This growing prescription rate is a source of concern for healthcare providers and healthcare economists alike

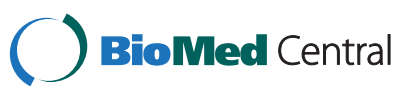


$[8,10]$. The explanations for this high prescription rate remain unclear, with little consensus, and the reasons behind the phenomenon remain largely unknown $[11,12]$. According to the literature, there are two main causes for this situation. The first is over-prescription for psychiatric conditions. Evidence does not show ADs to be highly clinically effective in treating moderate depression, which is frequently encountered in PC settings, although several recent studies have found that ADs could possibly be beneficial in treating milder episodes $[13,14]$. ADs are sometimes discontinued too early or prescribed too long $[15,16]$. Assessing the potential benefit of $\mathrm{AD}$ prescription seems to be a challenge, as the variations in measurement specifications in the studies impact the conclusions that are drawn about treatment of depression [17]. The second reason is the prescription of ADs for "non-psychiatric conditions". Growing evidence points to ADs being frequently prescribed for conditions or health problems outside the field of psychiatry [18]. Some observational data suggest that this proportion varies between $25 \%$ and $60 \%$ $[19,20]$. Exploratory research has confirmed that GPs prescribe ADs for many non-psychiatric conditions and off-label uses. In many fields, GPs used their feelings and feelings on the products' efficacy rather than scientific evidence to prescribe. [21]. The aim of this study was to review the level of evidence for the prescription for ADs in non-psychiatric PC conditions in order to help GPs in their daily practice.

\section{Methods}

The overall review process is summarised in Figure 1.

\section{Defining the limits of the searches}

To retrieve the level of evidence for the prescription of ADs in non-psychiatric PC settings, an initial search was performed using the MeSH terms for the 24 medical conditions collected in our previous qualitative study and the terms "antidepressants" and "therapeutic use" in PubMed [21]. During this process, 30 additional conditions possibly leading to $\mathrm{AD}$ prescription were found resulting in a list of 54 conditions or medical circumstances for which ADs could possibly be prescribed. Ten conditions - psychiatric disorders, non-primary care and non-adult conditions - were then excluded: five purely psychiatric disorders, narcolepsy and myotonia because of their low prevalence in primary care, nocturnal enuresis as a paediatric condition and amphetamine withdrawal and cocain dependence being conditions to be managed in multidisciplinary and specialised environment. This process resulted in a list of 44 non-psychiatric disorders manageable in $\mathrm{PC}$ and potentially leading to AD prescription in PC (Table 1). This list was used for the data collection search strategy.

\section{Data collection: search strategy}

The terms matching with the 44 conditions and medical circumstances for possible AD prescription were listed in French and English. The MeSH validated translation

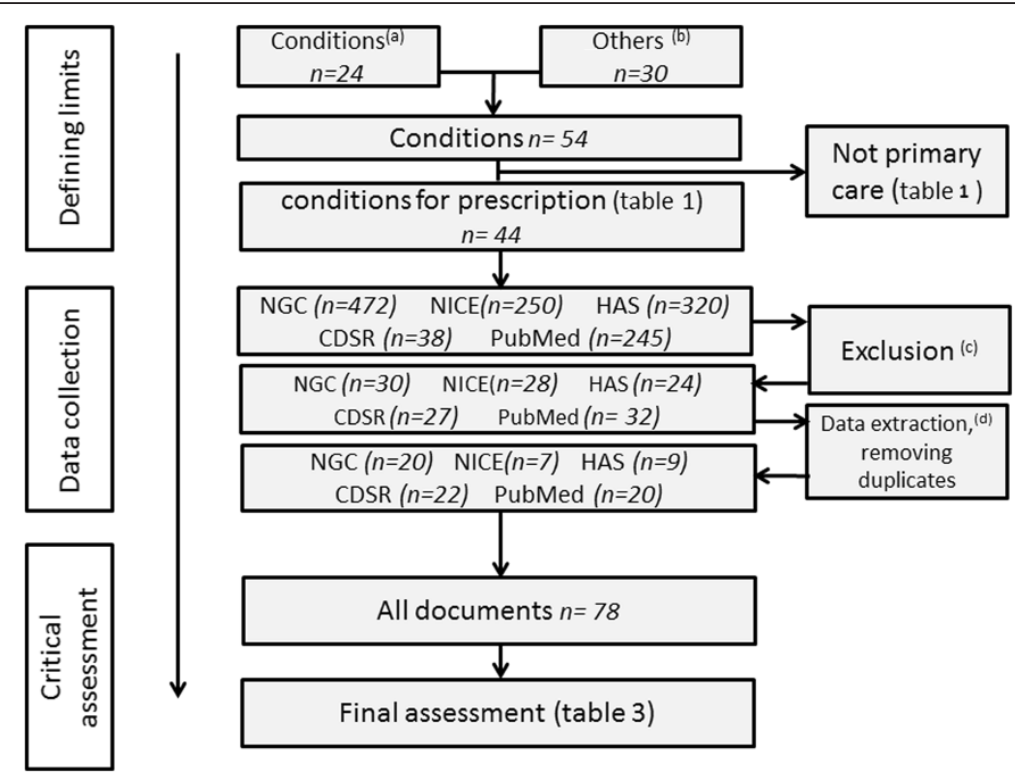

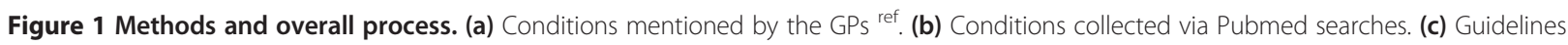
before 1997, paediatrics, nursing practices, patient information or education, medical records, continuous medical education for care providers, medical imaging, biology and surgical techniques. (d) Selection of the latest guidelines containing the key words (antidepressant", "Tricyclic agents", "TCA", "SNRI", "serotonin", "SSRI", "tricyclic", "imipramine", "monoamine", "duloxetine", "venlafaxine). 


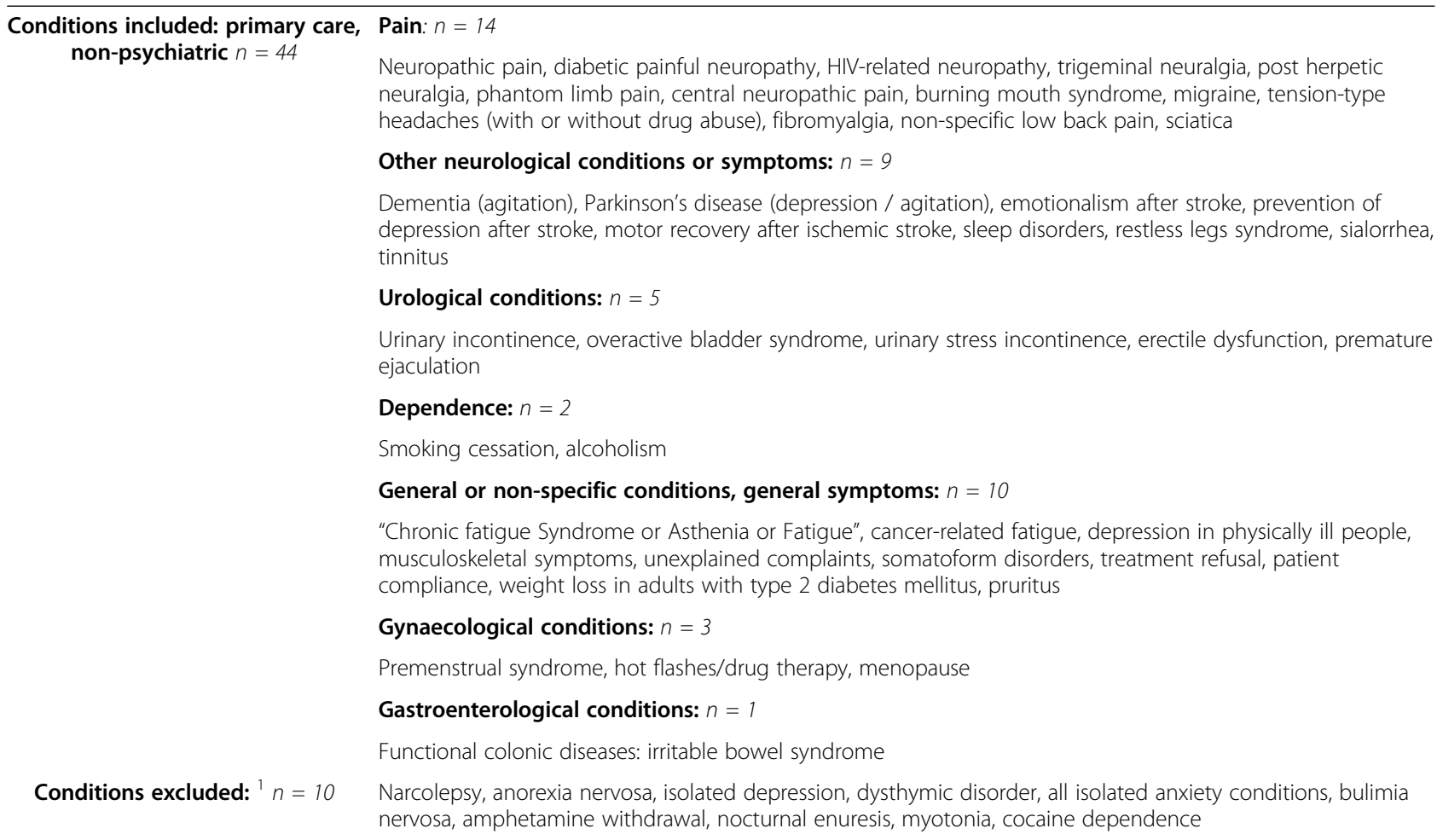

and synonyms were searched for in the terminology section of the catalogue and index of the French-language Health Resources Website (CISMeF). When there was no $\mathrm{MeSH}$ term available for the medical condition or circumstance, the researchers used a broader $\mathrm{MeSH}$ term, on a higher level of hierarchy, including the description (e.g., cancer AND antidepressants for "cancer related fatigue, musculoskeletal diseases AND antidepressants for musculoskeletal symptoms). Using this list, searches were performed to find the available guidelines (GL) in the databases of the following government agencies: the French "Haute Autorite de Santé" (HAS), the English National Institute for Clinical Excellence (NICE) and the National Guideline Clearinghouse (NGC), the last one including most international guidelines. The searches were performed from March 2011 to August 2011. The search covered all of the documents made available by the three agencies.

\section{Data collection: additional searches for updated data}

During the same period, we performed simultaneously, a search in the Cochrane database of systematic reviews (CDSR) and in Medline on the same basis, using the same criteria and process. For the Medline search, the following limits were used: "clinical trial, meta-analysis, clinical guidelines, randomized controlled trial, and adults, published after 2004". The aim was to find scientific data published after the launch of the guidelines.
Those studies might change the evidence and possibly lead to a change in prescription attitudes. All detailed searches are available in the full version of all guidelines. Individual studies (RCTs in Pubmed) included in this review did not constitute the bulk of the results.

\section{Data extraction}

All guidelines before 1997 were excluded, as were those regarding paediatrics, nursing practices, patient information or education, medical records, continuing medical education for care providers, medical imaging, biology and surgical techniques. Full text of guidelines have been downloaded from the agencies databases. All nonpsychiatric conditions were included and all standalone psychiatric conditions were excluded. Remaining documents on anxiety, depression and side effects of ADs were also excluded after reading. The documents were independently read and assessed by two researchers (AM \& IAA) and disagreements were resolved by discussion. Duplicates were removed. The documents in the databases were crosschecked using a search with the generic term "antidepressants" in order to retrieve any documents that may have been missed by previous searches. In the full text documents, the terms "antidepressant", "Tricyclic agents", "TCA", "SNRI", "serotonin", "SSRI", "tricyclic", "imipramine", "monoamine", "duloxetine", "venlafaxine" and their French translations were searched for. All guidelines containing the key- 
words were selected. In order to find the latest evidence, the most recent documents available on each topic in each guideline database were retained when available, and the most up-to-date version of the selected guidelines was kept. The overall process ended with a list of 78 documents.

\section{Critical assessment}

The final stage of the study aimed to retrieve guidelines on recommended therapeutic use of ADs from these documents. Sections of specific interest were extracted and analysed. Information on pharmaceutical classes, drugs, recommended therapeutic use and level of evidence was collected when available. Agreements and discordances were noted, and inconsistencies between the various guidelines were highlighted. Recommendations from the guidelines were graded according to the EFNS scheme [22] (Additional file 1).

\section{Results}

We collected 1,325 documents on 44 conditions. After exclusion, 141 remained. After applying our criteria for data extraction, 78 documents were retrieved, including 36 GLs, 38 reviews or systematic reviews (some followed by a meta-analysis) and 4 RCTs. The guidelines enabled us to describe the evidence for $\mathrm{AD}$ prescription for 27 conditions. For 14 conditions, searches in CDSR and PubMed retrieved updated information. For 3 conditions (somatoform disorders, treatment refusal, and patient compliance), no data were found. Among the 44 conditions, ADs were found to be potentially beneficial with a high level of evidence in treating 15 conditions and potentially beneficial with a lower level of evidence in treating 5 others. No proof of benefit was found for 15 conditions and proof of no benefit for 9. All results are detailed in Table 2.

\section{Pain conditions}

All results for pain conditions are described in Table 3.

\section{Neurological conditions}

The guidelines, reviews and RCTs found prescription of sertraline, citalopram and trazodone to be potentially beneficial in treating behavioural perturbations, mood disorders and agitation in patients with dementia, though no level of evidence was available $[40,41]$. Potential side effects and difficulty in managing the prescription were emphasised [42]. ADs were found to have no specific effects in treating Parkinson's disease, apart from those in treating its associated psychiatric indications [43].

Concerning stroke, three kinds of problems were assessed: treatment of emotionalism, prevention of depression and the benefit of prescribing an $A D$ in the acute stage to facilitate recovery of motor skills. ADs were recommended for emotional instability (Level B) $[44,45]$. They reduced the frequency and severity of crying and laughing episodes. The effect did not seem

Table 2 Assessment of AD usefulness

\begin{tabular}{|c|c|}
\hline & $\begin{array}{l}\text {-Neuropathic pain (neuralgia and painful polyneuropathy), diabetic painful neuropathy, central neuropathic pain, migraine, } \\
\text { tension-type headaches, fibromyalgia }\end{array}$ \\
\hline Useful $^{(1)}$ & -Urinary stress incontinence, premature ejaculation \\
\hline \multirow[t]{3}{*}{$n=15$} & -Prevention of depression after stroke, emotionalism after stroke -Smoking cessation \\
\hline & -Premenstrual syndrome, hot flashes/drug therapy, hot flashes during menopause \\
\hline & -Irritable bowel syndrome \\
\hline Possibly useful ${ }^{(2)}$ & -Post herpetic neuralgia, trigeminal neuralgia \\
\hline \multirow[t]{2}{*}{$n=5$} & -Agitation in dementia, motor recovery after ischemic stroke \\
\hline & -Overactive bladder syndrome \\
\hline $\begin{array}{l}\text { No proof of } \\
\text { benefit }\end{array}$ & - Tension-type headaches with drug abuse, sciatica, Parkinson's disease, sleep disorders \\
\hline \multirow[t]{3}{*}{$n=15$} & - pruritus \\
\hline & - Asthenia- fatigue-chronic fatigue syndrome, cancer-related fatigue, depression in physically ill people \\
\hline & $\begin{array}{l}\text { - Unexplained complaints, somatoform disorders, treatment refusal, patient compliance, weight loss in adults with } \\
\text { type } 2 \text { diabetes }\end{array}$ \\
\hline $\begin{array}{l}\text { Proof of no } \\
\text { benefit }\end{array}$ & -HIV related neuropathy, phantom limb pain, burning mouth syndrome, non-specific low back pain, restless legs syndrome \\
\hline \multirow[t]{3}{*}{$n=9$} & -Other urinary incontinence conditions, erectile dysfunction -Alcoholism / \\
\hline & alcohol misuse \\
\hline & -Musculoskeletal symptoms ${ }^{(5)}$ \\
\hline
\end{tabular}

(1) Recommended with evidence level mentioned or recent meta-analysis. (2) Mentioned without level of evidence, or second line treatment, or only RCTs. (3) Not enough or no data, apart from psychiatric condition. (4) No benefit mentioned in RCTs or reviews. (5) See fibromyalgia in Table 3. 
Table 3 ADs in pain conditions ${ }^{1}$

\begin{tabular}{|c|c|c|}
\hline Condition & $\begin{array}{c}A D \text { treatment, role in strategy, rating of the } \\
\text { recommendation }\end{array}$ & Comments and role of other treatments \\
\hline \multirow{4}{*}{$\begin{array}{l}\text { Neuralgia and } \\
\text { painful } \\
\text { polyneuropathy } \\
{[22-26]}\end{array}$} & ADs recommended: & -Similar statements between guidelines: \\
\hline & $\begin{array}{l}\text {-TCAs: Amitriptyline first line (25-150 mg/day, Level A) } \\
\text { Nortriptyline (alternative option) [22-26] NNT of } 3.6 \text { ( } 95 \% \text { Cl: 3-4.5). }\end{array}$ & -Strong consensus for TCAs and venlafaxine. \\
\hline & $\begin{array}{l}\text {-SNRIs: Venlafaxine, fist line treatment (Level A) NNT of } 3.1 \\
\text { Duloxetine: option }\end{array}$ & \multirow{2}{*}{$\begin{array}{l}\text {-Gabapentin, Pregabalin: also recommended as first-line } \\
\text { treatments. TCAs are equally effective compared to non-AD } \\
\text { drugs gabapentin (1200-3600 mg/day) and pregabalin (150- } \\
600 \text { mg/day) }\end{array}$} \\
\hline & SSRI: not recommended & \\
\hline \multirow{4}{*}{$\begin{array}{l}\text { Painful Diabetic } \\
\text { Neuropathy (PDN) } \\
\text { [25-29] }\end{array}$} & ADs recommended: & \\
\hline & $\begin{array}{l}\text {-Duloxetine } 60 \mathrm{mg} \text { and } 120 \mathrm{mg} \text { daily, first-line, (Level A) The } \\
\text { NNT for effectiveness was } 1.3(95 \% \mathrm{Cl}: 1.2-1.5) \text {. This AD has } \\
\text { on-label use for this condition }[25,26,28]\end{array}$ & $\begin{array}{l}\text { Duloxetine: conflicting evidence between guidelines, just } \\
\text { cited as a therapy for NP in the EFNS GL[24], and only for } \\
\text { PDN in the Cochrane Review }\end{array}$ \\
\hline & $\begin{array}{l}\text {-Venlafaxine } 150-225 \mathrm{mg} / \mathrm{day} \text {; first line (no level mentioned) } \\
\text { TCA : If other ADs contraindicated, Amitriptyline is an option }\end{array}$ & \multirow{2}{*}{$\begin{array}{l}\text { Venlafaxine might be added to gabapentin for a better } \\
\text { response (Level C). }\end{array}$} \\
\hline & SSRIS: not recommended & \\
\hline \multirow[b]{2}{*}{$\begin{array}{c}\text { HIV-related } \\
\text { neuropathies [27] }\end{array}$} & & -Evidence not to prescribe any AD \\
\hline & No $A D$ treatment recommended & $\begin{array}{l}\text { - Recommended non-AD treatments: -lamotrigine (Level B), } \\
\text { smoking cannabis (Level A), capsaicin patches (Level A) }\end{array}$ \\
\hline $\begin{array}{l}\text { Phantom limb } \\
\text { pain [30] }\end{array}$ & No $A D$ treatment recommended & Amitriptyline was not different from placebo \\
\hline \multirow{2}{*}{$\begin{array}{c}\text { Trigeminal } \\
\text { neuralgia }[25,26]\end{array}$} & $-A D s$ are not first-line treatment & $\begin{array}{l}\text {-Similar statements but lack of comparative trials to assess a } \\
\text { precise role for TCAs and venlafaxine. }\end{array}$ \\
\hline & $\begin{array}{l}\text {-ADs recommended: TCA or venlafaxine are alternative } \\
\text { treatments }\end{array}$ & First-line: carbamazepine (Level A) and oxcarbazepine (Level B) \\
\hline \multirow[t]{2}{*}{$\begin{array}{l}\text { Postherpetic } \\
\text { neuralgia }[25,26]\end{array}$} & $-A D s$ are not first-line treatments & $\begin{array}{l}\text {-Similar statements but lack of comparative trials to assess a } \\
\text { precise role for TCAs and venlafaxine }\end{array}$ \\
\hline & $\begin{array}{l}\text { - ADs recommended: TCA or venlafaxine are alternative } \\
\text { treatments }\end{array}$ & -First-line: gabapentin / pregabalin (Level A) \\
\hline \multirow[t]{2}{*}{ Central pain ${ }^{2}[24]$} & -ADs are not first-line treatment & -Similar statements between guidelines \\
\hline & $\begin{array}{l}\text { - ADs recommended: TCAs: Amitriptyline second-line (Level B)- } \\
\text { SNRIs: Duloxetine and venlafaxine second choice (Level B) }\end{array}$ & -Pregabalin: first-line (level A) \\
\hline \multirow{3}{*}{$\begin{array}{l}\text { Migraine and } \\
\text { tension type } \\
\text { headaches [31-34] }\end{array}$} & ADs recommended: & $\begin{array}{l}\text {-Similar statements for TCAs, and SSRIs. Disagreement for the } \\
\text { usefulness of venlafaxine }\end{array}$ \\
\hline & $\begin{array}{l}\text {-TCA: Amitryptiline } 25-150 \mathrm{mg} \text { per day, (Level A).-Venlafaxine } \\
75-150 \mathrm{mg} \text { was presented as an effective alternative to } \\
\text { tricyclic antidepressants (Level B) }\end{array}$ & $\begin{array}{l}\text {-TCA: In cases of TTH with associated drug abuse, the role of } \\
\text { this treatment was only mentioned, with no rating, by the } \\
\text { French HAS. }\end{array}$ \\
\hline & SSRIs: not recommended & \\
\hline \multirow{2}{*}{$\begin{array}{l}\text { Sciatica, non-specific } \\
\text { low back pain } \\
{[35-37]}\end{array}$} & No $A D$ treatments recommended & $\begin{array}{l}\text { Only to be prescribed as an option in the event of associated } \\
\text { depression (NICE) }\end{array}$ \\
\hline & & $\begin{array}{l}\text { Very weak evidence for TCAs observed by the French HAS } \\
\text { (level C) }\end{array}$ \\
\hline \multirow[t]{4}{*}{ Fibromyalgia $^{3}[28,38]$} & ADs recommended: & \multirow[t]{4}{*}{ Alternative pharmacological options: Gabapentin, tramadol } \\
\hline & $\begin{array}{l}\text { SNRIs: Milnacipran } 12.5 \text { mg once daily, target dose of 50-100 } \\
\text { mg two times per day }\end{array}$ & \\
\hline & $\begin{array}{l}\text {-Duloxetine: } 60 \mathrm{mg} \text { twice daily, -Venlafaxine could be } \\
\text { prescribed -TCAs showed evidence }\end{array}$ & \\
\hline & SSRIS: not recommended & \\
\hline $\begin{array}{l}\text { Burning mouth } \\
\text { syndrome }[39]\end{array}$ & No $A D$ treatments recommended & -Two RCTs showed no antidepressant effects \\
\hline
\end{tabular}

(1) Neuropathic pain is related to different treatment strategies and different conditions detailed in this table.

(2) Diffuse pain, refractory or recurrent pain, central pain, pain connected with multiple sclerosis, dysesthesia after stroke or paraplegia.

(3) See also comments in plain text: General or non-specific conditions and general symptoms. 
specific to one drug or class of drugs. Early prescription prevented depression, but no improvement in its severity was found when depression was actually occurring [46]. Early prescription of fluoxetine with physiotherapy found that patients with ischemic stroke and moderate to severe motor deficit could enhance motor recovery after 3 months [47].

Antidepressants were found to provide no benefit in treating isolated sleeping disorders and primary insomnia even though they were found to be potentially beneficial in the event of psychiatric comorbidity [48].

Antidepressants were not recommended for use in cases of restless legs syndrome, which was in fact presented as a side effect of ADs [49].

As well, there was no evidence of a benefit in prescribing ADs for cases of sialorrhea related to neurological conditions (Amyotrophic lateral sclerosis (ALS), Parkinson's disease), although prescription was sometimes recommended [50]. Antidepressants were found to have no proof of benefit for cases of tinnitus [51].

\section{Urological and gynaecological conditions}

Duloxetine was found to have potential benefits as a second-line (Level C) treatment for patients with stress urinary incontinence. Duloxetine significantly improved quality of life but TCAs did not. Anticholinergic agents, such as TCAs, were found to have potential benefits for patients with overactive bladder syndrome [52-54]. Proof of benefit was observed for incontinence caused by other urological conditions. Antidepressants were cited as a potential source of side effects for these conditions [55].

One Cochrane review attested that all SSRIs were highly effective in reducing symptoms related to severe premenstrual syndrome, (also called pre-menstrual dysphoric disorder or luteal phase dysphoric disorder) (SMD -0.53, 95\% CI: 0.68 to -0.39 ; P $<0.00001$ ) with no level of evidence available [56]. Another Cochrane review reported that SSRIs and SNRIs had a mild to moderate effect in reducing hot flashes during menopause in women with a history of breast cancer, as well as in men with a history of prostate cancer (Level B) [57].

SSRIs were not recommended for erectile dysfunction. They were, however, recommended as a first-line (Level A) treatment for premature ejaculation $[58,59]$.

\section{Dependence}

Nortriptyline was shown to be effective for tobacco withdrawal (OR 2.79 (95\% CI: 1.70-4.59) whereas moclobemide, venlafaxine and SSRIs did not show any effectiveness (no level of evidence available) [60]. All guidelines and reviews agreed that ADs were not indicated for alcohol misuse or dependence [61]. It is clearly stated that depression is a direct consequence of alcohol abuse, and that $\mathrm{AD}$ prescription is useless if the patient does not stop drinking.

General or non-specific conditions and general symptoms The term "fatigue" pooled together a wide variety of health problems. No data was retrieved for isolated fatigue. In the NICE guideline, ADs were not found to be beneficial in treating chronic fatigue syndrome. ADs were considered as useless for cancer-related fatigue but beneficial in treating depression related to purely physical conditions, with no effect on the physical conditions themselves [62].

Prescribing an AD provided no benefit for musculoskeletal symptoms, except for fibromyalgia, which is assessed in the "pain conditions" section of the results (see also Table 3) [63]. No data was retrieved regarding prescription for unexplained complaints, somatoform disorders, treatment refusal, chronic pruritus, helping type 2 diabetes patients to lose weight, and improving medical adherence or patient compliance.

\section{Gastroenterological conditions}

According to the CDSR, TCAs could be used as a second-line treatment and SSRIs as a third-line treatment, for irritable bowel syndrome (IBS) (no level of evidence available) $[64,65]$.

\section{Discussion}

\section{Summary of the main results}

Antidepressants were found to be potentially useful with a high level of evidence for 15 conditions and potentially useful with a lower level of evidence for 5 others. Prescribing an $\mathrm{AD}$ was found to be potentially beneficial for patients with many pain conditions as well as urological, gastroenterological and gynaecological conditions. Nevertheless, while prescribing, the GP has to refer to on-label use for his own country, because unfortunately, proof of benefit is not related to "on label use". The evidence reviewed provided insufficient support for prescribing ADs for 24 other conditions. Restless legs syndrome, non-specific urinary incontinence and erectile dysfunction exposed in the "proof of no benefit" section were side effects of ADs. For rheumatologic conditions, (musculoskeletal symptoms and non-specific low back pain) the "proof of no benefit" should be interpreted with caution, due to the difficulty in assessing these patients in a primary care setting. Pain symptoms or somatoform complaints may be similar to those encountered in fibromyalgia, a clinical syndrome that lacks a clear definition and is still a subject of debate [66]. For the other 15 conditions listed in the "No proof of benefit" section, this should be understood as "having no specific effect on the non-psychiatric condition mentioned". For example, no guidelines found ADs to have a specific 
effect in treating Parkinson's disease comparable to their effect in treating dementia-related agitation. Nevertheless, ADs should be prescribed in the event of a major depressive episode related to Parkinson. The same can be said for treating depression in physically ill people or those with cancer [62]. Thus, an AD considered as having no specific benefit for a given condition may prove beneficial for certain specific PC patients. As a result, it is difficult for prescribing physicians to assess the potential benefit of using them in clinical practice in PC settings where several conditions are involved.

\section{Strengths and limitations of the study}

The first strength of the study was the meticulous methodology and careful step-by-step process used to extract the data. The analysis was not started from a theoretical framework, but from real daily practice in primary care, based on the qualitative material of our previous research [21]. No previous study has assessed in that way the appropriateness of $\mathrm{AD}$ prescriptions for non-psychiatric conditions. This review gives a new insight on studies emphasizing misuse as an explanation for the increasing rate of $\mathrm{AD}$ prescription [67-70]. A second strength was that it provided all GPs a clear overview of information on ADs not limited to the information and guidelines available in their own country. Finally, a third strength of the study was that it updated the guidelines with recent reviews, in order not to miss relevant information. This study, being an analysis of guidelines and systematic reviews did not focus on a single condition, population or intervention, but on a family of drug (ADs) and their indications. Thus, the nature of this analysis made it impossible to perform a systematic review fulfilling the "Prisma" statements. Another limitation of this study was the consistency of the available data. First of all, levels of evidence were not always available. When available, levels of evidence were not always consistent between the different guidelines, as was the case with diabetic painful neuropathy. Additionally, either a given $\mathrm{AD}$, only certain $\mathrm{ADs}$ or an entire class of ADs could be considered as having a potential benefit in treating a specific condition. For example, among the SSRIs, only citalopram and sertraline were assessed in treating dementia-related agitation. Also, the optimum dosage to be used in treating a condition was not always determined, as in the case of using amitryptiline to treat migraine or neuropathic pain. Finally a limitation of our study could be that some guidelines in other languages than French and English were not selected in the search. However we used the big databases such as Medline and NGC, which already include guidelines, sometimes translated in English, from many guideline developers worldwide.

Performing a strict assessment and comparison of several conditions appeared arduous: although the subjects of the recommendations were similar, the guidelines did not refer to strictly comparable conditions. For example difficulties were encountered with fibromyalgia, chronic fatigue syndrome and rheumatologic pain, which were difficult to distinguish from one another. This lack of precision can lead to difficulties in assessing and summarizing information, and consequently in correctly understanding the potential benefit of ADs for patients. As well, the randomised trials were designed for well-defined conditions and homogeneous populations, which is rarely the case for PC patients. The inclusion criteria for the studies often involved secondary care and did not reflect primary care situations.

The limitations of available data and the wide variety of conditions made it difficult to formulate clear recommendations. In any case, the results of the study provide new insight to enable clinicians to prescribe ADs with more accuracy, and could potentially serve as a point of reference for health policy organizations in specifying prescription rules.

\section{Consistency of GPs' prescriptions with the evidence}

Comparing the 24 non-psychiatric health conditions for which the GPs claimed to prescribe ADs [21] with the results of this review study, 12 conditions were found to be based on evidence. Of the 12 other conditions for which GPs claimed a prescription of an AD, there was no scientific evidence. In our qualitative study, the GPs correctly assessed the benefit of ADs in treating pain conditions [21]. This seems contradictory with observational studies finding that pain management could be improved in PC settings [71]. However GPs' proper assessment of the benefit of ADs, depends on his ability to make a fine distinction between "the scientifically proven effect of an $\mathrm{AD}$ for a certain condition" and "the potential benefit of an $\mathrm{AD}$ at the right dose for a specific patient presenting with several psychiatric or non-psychiatric conditions". Besides the GP's decision is based not only on biomedical observations, but also follows a bio-psychosocial model in which patient-centeredness and the environment are taken into account [67]. The major benefit of this study is to understand better and justify GPs' AD prescription behaviour.

\section{Implications for future research}

On the whole, the guideline agencies often stressed a lack of head-to-head comparative trials assessing the clinical effectiveness of the drugs, which would allow physicians to prioritise the choice of therapy for a given condition. This is impossible without any involvement from healthcare institutions. Another challenge is to better understand the way physicians prescribe ADs in actual PC settings. We currently know that GPs' decisions are shaped by a combination of diseases and psychosocial influences. The potential benefit of a prescription for a patient cannot be assessed without incorporating 
all of the dimensions of actual prescription. This requires a strict comparison that directly assesses the prescriptions, indications and patients' environment, based on observational cohort studies to collect data on medical conditions, psychosocial environment and prescriptions in PC settings.

\section{Conclusions}

Prescription of ADs was found to be useful for many non-psychiatric health conditions commonly encountered in primary care. Evidence against prescribing ADs was also found. The overall inconsistency of available information hindered precise assessment of the evidence. There remains much uncertainty as regards the role of prescribing ADs in therapeutic strategies, as well as the appropriateness and accuracy AD prescriptions. It is important to emphasise the difference between assessing the scientifically proven effect of an $\mathrm{AD}$ for a certain condition and the potential benefit of an $\mathrm{AD}$ at the right dose for a specific patient despite a lower level of evidence. Further studies are required to provide physicians more comprehensive knowledge and to improve patient care.

\section{Additional file}

Additional file 1: Rating of recommendations.

\begin{abstract}
Abbreviations
AD(s): Antidepressant(s); ALS: Amyotrophic lateral sclerosis; CDSR: Cochrane database of systematic reviews; Cismef: Catalogue and index of the Frenchlanguage health resources; HAS: French "haute autorite de sante"; IBS: Irritable bowel syndrome; NICE: English National Institute for clinical excellence; NGC: National guideline clearinghouse; PC: Primary care: SMD: Standardized mean difference; TCA: Tricyclic agent; SSRI: Selective serotonin reuptake inhibitors; SNRIs: Selective norepinephrine reuptake inhibitors.
\end{abstract}

\section{Competing interests}

The authors declare that they have no competing interests.

\section{Authors' contributions}

Conception of the idea for the study: AM. Development of the protocol: AM, IAA, JPL, MS, and PB. Data collection and extraction: AM, IAA, JPL. Critical assessment: AM, IAA, JPL, MS, and PB. PVR and LP participated in the design and coordination and helped to draft the manuscript. Writing of the manuscript: AM. All of the authors have read the draft critically, to make contributions, and have approved the final text.

\section{Acknowledgements}

The authors thank honorary Professor François Becret, and Pr Jacques Weber, and $\operatorname{Pr}$ Stefan Darmoni for their friendly support. We thank the Scientific Committee of the CIC-INSERM-Rouen University Hospital for reviewing the protocol corresponding to this study. Thanks to our English editor, Stephen Martin, for his proofreading and advices.

\section{Funding}

This work was not supported by any funding.

\section{Author details}

'Department of General Practice, Rouen University and CIC Inserm 0204, University of Rouen, Rouen, France. ${ }^{2}$ Department of General Practice, Denis
Diderot Paris 7 University, Paris, France. ${ }^{3}$ Department of General Practice, Tours University, Tours, France. ${ }^{4}$ Department of Primary and Interdisciplinary Care, Faculty of Medicine and Health Science, University of Antwerp, Antwerp, Belgium. ${ }^{5}$ Department of Public Health, Vrije Universiteit Brussel, Brussels, Belgium.

Received: 20 November 2012 Accepted: 24 April 2013

Published: 4 May 2013

\section{References}

1. Gasquet I, Nègre-Pagès L, Fourrier A, Nachbaur G, El-Hasnaoui A, Kovess V, Lépine J-P: [Psychotropic drug use and mental psychiatric disorders in France; results of the general population ESEMeD/MHEDEA 2000 epidemiological study]. Encephale 2005, 31:195-206.

2. Olfson M, Marcus SC: National patterns in antidepressant medication treatment. Arch Gen Psychiatry 2009, 66:848.

3. Ventes de médicaments aux officines et aux hôpitaux en France: chiffres clés 2010. Rapport d'expertise. (Sales of medicines to pharmacies and hospitals in France: key figures 2010. Expertise). http://ansm.sante.fr/content/download/ 35989/470166/version/4/file/chiffres-cle-venteMedicaments2010.pdf.

4. Alonso J, Angermeyer MC, Bernert S, Bruffaerts R, Brugha TS, Bryson H, De Girolamo G, Graaf R, Demyttenaere K, Gasquet I, Haro JM, Katz SJ, Kessler RC, Kovess V, Lépine JP, Ormel J, Polidori G, Russo LJ, Vilagut G, Almansa J, Arbabzadeh-Bouchez S, Autonell J, Bernal M, Buist-Bouwman MA, Codony M, Domingo-Salvany A, Ferrer M, Joo SS, Martínez-Alonso M, Matschinger H, et al: Psychotropic drug utilization in Europe: results from the European Study of the Epidemiology of Mental Disorders (ESEMeD) project. Acta Psychiatr Scand Supp/ 2004, 109:55-64.

5. Lepine J, Gasquet IF: [Psychotropic drug use in France: changes over time and comparison with other European countries]. Bull Acad Natl Med 2006, 190:1139-1145.

6. Ciuna A, Andretta M, Corbari L, Levi D, Mirandola M, Sorio A, Barbui C: Are we going to increase the use of antidepressants up to that of benzodiazepines? Eur J Clin Pharmacol 2004, 60:629-634.

7. Petty DR, House A, Knapp P, Raynor T, Zermansky A: Prevalence, duration and indications for prescribing of antidepressants in primary care. Age Ageing 2006, 35:523-526.

8. Chen Y, Kelton CML, Jing Y, Guo JJ, Li X, Patel NC: Utilization, price, and spending trends for antidepressants in the US Medicaid Program. Res Social Adm Pharm 2008, 4:244-257.

9. Mojtabai R, Olfson M: National patterns in antidepressant treatment by psychiatrists and general medical providers: results from the national comorbidity survey replication. J Clin Psychiatry 2008, 69:1064-1074.

10. Coupland CAC, Dhiman P, Barton G, Morriss R, Arthur A, Sach T, Hippisley-Cox $\mathrm{J}$ : A study of the safety and harms of antidepressant drugs for older people: a cohort study using a large primary care database. Health Technol Assess 2011, 15:1-202. iii-iv.

11. Grolleau A, Cougnard A, Bégaud B, Verdoux H: [Psychotropic drug use and correspondence with psychiatric diagnoses in the mental health in the general population survey]. Encéphale 2008, 34:352-359.

12. Piek E, van der Meer K, Hoogendijk WJG, Penninx BWJH, Nolen WA: Most antidepressant use in primary care is justified; results of the netherlands study of depression and anxiety. PLoS One 2011, 6:e14784.

13. Arroll B, Elley CR, Fishman T, Goodyear-Smith FA, Kenealy T, Blashki G, Kerse N, MacGillivray S: Antidepressants versus placebo for depression in primary care. Cochrane Database Syst Rev 2009(Issue 3):Art. No.: CD007954. doi:10.1002/ 14651858. CD007954.

14. Stewart JA, Deliyannides DA, Hellerstein DJ, McGrath PJ, Stewart JW: Can people with nonsevere major depression benefit from antidepressant medication? J Clin Psychiatry 2012, 73:518-525.

15. Serna MC, Cruz I, Real J, Gascó E, Galván L: Duration and adherence of antidepressant treatment (2003 to 2007) based on prescription database. Eur Psychiatry 2010, 25:206-213.

16. Moore M, Yuen HM, Dunn N, Mullee MA, Maskell J, Kendrick T: Explaining the rise in antidepressant prescribing: a descriptive study using the general practice research database. BMJ 2009, 339:b3999.

17. Kerr EA, McGlynn EA, Van Vorst KA, Wickstrom SL: Measuring antidepressant prescribing practice in a health care system using administrative data: implications for quality measurement and improvement. It Comm J Qual Improv 2000, 26:203-216. 
18. Mojtabai R, Olfson M: Proportion of antidepressants prescribed without a psychiatric diagnosis is growing. Health Aff 2011, 30:1434-1442.

19. Chen H, Reeves JH, Fincham JE, Kennedy WK, Dorfman JH, Martin BC: Off-label use of antidepressant, anticonvulsant, and antipsychotic medications among Georgia medicaid enrollees in 2001. J Clin Psychiatry 2006, 67:972-982.

20. Larson MJ, Miller K, Fleming KJ: Treatment with antidepressant medications in private health plans. Adm Policy Ment Health 2007, 34:1 16-126.

21. Mercier A, Auger-Aubin I, Lebeau J-P, Van Royen P, Peremans L: Understanding the prescription of antidepressants: a qualitative study among French GPs. BMC Fam Pract 2011, 12:99.

22. Brainin M, Barnes M, Baron J-C, Gilhus NE, Hughes R, Selmaj K, Waldemar G Guidance for the preparation of neurological management guidelines by EFNS scientific task forces-revised recommendations 2004. Eur I Neurol 2004, 11:577-581.

23. Haute autorité de santé (HAS): Quelle place pour la prégabaline dans les douleurs neuropathiques (What place for pregabalin in neuropathic pain ?). Paris: HAS; 2007.

24. Attal N, Cruccu G, Baron R, Haanpää M, Hansson P, Jensen TS, Nurmikko T: EFNS guidelines on the pharmacological treatment of neuropathic pain: 2010 revision. Eur I Neurol 2010, 17:1113-e88.

25. National Institute for Health and Clinical Excellence: The pharmacological management of neuropathic pain in adults in non-specialist settings. [CG96] London: National Institute for Health and Clinical Excellence; 2010.

26. Dharmshaktu P, Tayal V, Kalra BS: Efficacy of antidepressants as analgesics: a review. J Clin Pharmacol 2012, 52:6-17.

27. Saarto T, Wiffen PJ: Antidepressants for neuropathic pain: a Cochrane review. J. Neurol. Neurosurg. Psychiatr. 2010, 81:1372-1373.

28. Lunn MPT, Hughes RAC, Wiffen PJ: Duloxetine for treating painful neuropathy or chronic pain. Cochrane Database Syst Rev 2009(Issue 4):Art. No. CD007115. doi:10.1002/14651858. CD007115.pub2.

29. Bril V, England J, Franklin GM, Backonja M, Cohen J, Del Toro D, Feldman E, Iverson DJ, Perkins B, Russell JW, Zochodne D: Evidence-based guideline: Treatment of painful diabetic neuropathy: report of the American Academy of Neurology, the American Association of Neuromuscular and Electrodiagnostic Medicine, and the American Academy of Physical Medicine and Rehabilitation. Neurology 2011, 76:1758-1765.

30. Alviar MJM, Hale T, Dungca M: Pharmacologic interventions for treating phantom limb pain. Cochrane Database Syst Rev 2011 (Issue 12):Art. No. CD006380. doi:10.1002/14651858. CD006380.pub2.

31. Scottish Intercollegiate Guidelines Network (SIGN): Diagnosis and management of headache in adults. A national clinical guideline. Edinburgh (Scotland): SIGN; 2008.

32. Evers S, Afra J, Frese A, Goadsby PJ, Linde M, May A, Sándor PS: EFNS guideline on the drug treatment of migraine-revised report of an EFNS task force. Eur J Neurol 2009, 16:968-981.

33. Moja L, Cusi C, Sterzi R, Canepari C: Selective serotonin re-uptake inhibitors (SSRls) for preventing migraine and tension-type headaches. Cochrane Database Syst Rev 2005(Issue 3):Art. No. CD002919. doi:10.1002/ 14651858. CD002919.pub2.

34. Agence national d'accréditation et d'évaluation en santé (ANAES): Recommandations pour la pratique clinique CCQ (Céphalées chroniques quotidiennes): Diagnostic, Rôle de l'abus médicamenteux, Prise en charge. (Guidelines for diagnostic, management of Chronic daily headache. Role of Substance-related disorders). Paris: ANAES; 2004

35. Agence national d'accréditation et d'évaluation en santé (ANAES): Prise en charge diagnostique et thérapeutique des lombalgies et lombosciatiques communes de moins de 3 mois d'évolution. . (Diagnosis and therapeutic management of acute low back pain, and sciatica). Paris: ANAES; 2000.

36. National Institute for Health and Clinical Excellence (NICE): Low back pain Early management of persistent non-specific low back pain, Clinical guidelines, CG88. ; 2009.

37. Urquhart DM, Hoving JL, Assendelft WJJ, Roland M, van Tulder MW: Antidepressants for non-specific low back pain. Cochrane Database Syst Rev 2008(Issue 1):Art. No. CD001703. doi:10.1002/14651858. CD001703.pub3.

38. Institute for Clinical Systems Improvement (ICSI): Assessment and management of chronic pain. Bloomington (MN): Institute for Clinical Systems Improvement (ICSI); 2009. Nov. 91 p. [187 references].

39. Zakrzewska JM, Forssell H, Glenny A-M: Interventions for the treatment of burning mouth syndrome. Cochrane Database Syst Rev 2005(Issue 1):Art. No. CD002779. doi:10.1002/14651858. CD002779.pub2.

40. Qaseem A, Snow V, Cross JT Jr, Forciea MA, Hopkins R Jr, Shekelle P, Adelman A, Mehr D, Schellhase K, Campos-Outcalt D, Santaguida P, Owens
DK: Current pharmacologic treatment of dementia: a clinical practice guideline from the American College of Physicians and the American Academy of Family Physicians. Ann Intern Med 2008, 148:370-378.

41. Seitz DP, Adunuri N, Gill SS, Gruneir A, Herrmann N, Rochon P: Antidepressants for agitation and psychosis in dementia. Cochrane Database Syst Rev 2011(Issue 2):Art. No. CD008191. doi:10.1002/14651858. CD008191.pub2.

42. Haute autorité de santé (HAS): Maladie d'Alzheimer et maladies apparentées: prise en charge des troubles du comportement perturbateurs, (Alzheimer's disease and Alzheimer's related diseases. Management of disruptive behaviour). Paris: HAS; 2009

43. Ghazi-Noori S, Chung TH, Deane K, Rickards HE, Clarke CE: Therapies for depression in Parkinson's disease. Cochrane Database Syst Rev 2003(Issue 3):Art. No:: CD003465. doi:10.1002/14651858.CD003465.

44. Hackett ML, Yang M, Anderson CS, Horrocks JA, House A: Pharmaceutical interventions for emotionalism after stroke. Cochrane Database Syst Rev 2010(Issue 2):Art. No. CD003690. doi:10.1002/14651858.CD003690.pub3.

45. Scottish Intercollegiate Guidelines Network: Management of patients with stroke: rehabilitation, prevention and management of complications, and discharge planning, A national clinical guideline; 2010. SIGN ISBN 9781 90581363 6, June 2010 [Available at http://www.sign.ac.uk/quidelines/ fulltext/118/]

46. Hackett ML, Anderson CS, House A, Halteh C: Interventions for preventing depression after stroke. Cochrane Database Syst Rev 2008(Issue 3):Art. No. CD003689. doi:10.1002/14651858. CD003689.pub3.

47. Chollet F, Tardy J, Albucher J-F, Thalamas C, Berard E, Lamy C, Bejot Y, Deltour S, Jaillard A, Niclot P: Fluoxetine for motor recovery after acute ischaemic stroke (FLAME): a randomised placebo-controlled trial. Lancet Neurol 2011, 10:123-130.

48. Schutte-Rodin S, Broch L, Buysse D, Dorsey C, Sateia M: Clinical guideline for the evaluation and management of chronic insomnia in adults. J Clin Sleep Med 2008, 4:487-504

49. Hoque R, Chesson AL Jr: Pharmacologically induced/exacerbated restless legs syndrome, periodic limb movements of sleep, and REM behavior disorder/REM sleep without atonia: literature review, qualitative scoring, and comparative analysis. J Clin Sleep Med 2010, 6:79-83.

50. Young CA, Ellis C, Johnson J, Sathasivam S, Pih N: Treatment for sialorrhea (excessive saliva) in people with motor neuron disease/amyotrophic lateral sclerosis. Cochrane Database Syst Rev 2011 (Issue 5):Art. No. CD006981. doi:10.1002/14651858. CD006981.pub2.

51. Baldo P, Doree C, Molin P, McFerran D, Cecco S: Antidepressants for patients with tinnitus. Cochrane Database Syst Rev 2012(Issue 9):Art. No. CD003853. doi:10.1002/14651858.CD003853.pub3.

52. Lucas M, Bosch R, Cruz F, de Ridder D, Neisius A, Pickard R, Schröder A Tubaro A, Turner W: 2010 addendum to 2009 urinary incontinence guidelines. Arnhem, The Netherlands: European Association of Urology (EAU); 2010:4.

53. Mariappan P, Alhasso AA, Grant A, N'Dow JMO: Serotonin and noradrenaline reuptake inhibitors (SNRI) for stress urinary incontinence in adults. Cochrane Database Syst Rev 2005(Issue 3):Art. No. CD004742. doi:10.1002/14651858. CD004742.pub2.

54. Roxburgh C, Cook J, Dublin N: Anticholinergic drugs versus other medications for overactive bladder syndrome in adults. Cochrane Database Syst Rev 2007:CD003190.

55. Agence Nationale d'Accréditation et d'Évaluation en Santé (ANAES): Prise en charge de lincontinence urinaire de la femme en médecine générale, Recommandations. (Guidelines for management of female urinary incontinence in general practice). Paris: ANAES; 2003.

56. Brown J, O'Brien PMS, Marjoribanks J, Wyatt K: Selective serotonin reuptake inhibitors for premenstrual syndrome. In Cochrane Database of Systematic Reviews. Edited by Brown J, The Cochrane Collaboration. Chichester, UK: John Wiley \& Sons, Ltd; 2009

57. Rada G, Capurro D, Pantoja T, Corbalán J, Moreno G, Letelier LM, Vera C Non-hormonal interventions for hot flushes in women with a history of breast cancer. Cochrane Database Syst Rev 2010(Issue 9):Art. No. CD004923. doi:10.1002/14651858.CD004923.pub2.

58. Hatzimouratidis K, Amar E, Eardley I, Giuliano F, Hatzichristou D, Montorsi F, Vardi $Y$, Wespes E: Guidelines on male sexual dysfunction: erectile dysfunction and premature ejaculation. Eur Urol 2010, 57:804-814.

59. Moreland AJ, Makela EH: Selective serotonin-reuptake inhibitors in the treatment of premature ejaculation. Ann Pharmacother 2005, 39:1296-1301. 
60. Hughes JR, Stead LF, Lancaster T: Antidepressants for smoking cessation. Cochrane Database Syst Rev 2007(Issue 1):Art. No. CD000031. doi:10.1002/ 14651858.CD000031.pub3.

61. National Institute for Health and Clinical Excellence (NICE): Alcohol-use disorders. Diagnosis, assessment and management of harmful drinking and alcohol dependence. CG 115 London: National Institute for Health and Clinical Excellence; 2011.

62. Rayner L, Price A, Evans A, Valsraj K, Higginson IJ, Hotopf M: Antidepressants for depression in physically ill people. Cochrane Database Syst Rev 2010(Issue 3):Art. No. CD007503. doi:10.1002/14651858. CD007503.pub2.

63. Perrot $\mathrm{S}$, Javier R-M, Marty M, Le Jeunne C, Laroche F: Is there any evidence to support the use of anti-depressants in painful rheumatological conditions? Systematic review of pharmacological and clinical studies. Rheumatology (Oxford) 2008, 47:1117-1123.

64. Ruepert L, Quartero AO, de Wit NJ, van der Heijden GJ, Rubin G, Muris JWM: Bulking agents, antispasmodics and antidepressants for the treatment of irritable bowel syndrome. Cochrane Database Syst Rev 2011 (Issue 8):Art. No. CD003460. doi:10.1002/14651858. CD003460.pub.

65. Ford AC, Talley NJ, Schoenfeld PS, Quigley EMM, Moayyedi P: Efficacy of antidepressants and psychological therapies in irritable bowel syndrome: systematic review and meta-analysis. Gut 2009, 58:367-378.

66. McKay PG, Duffy T, Martin CR: Are chronic fatigue syndrome and fibromyalgia the same? Implications for the provision of appropriate mental health intervention. J Psychiatr Ment Health Nurs 2009, 16:884-894.

67. Sleath B, Shih Y-CT: Sociological influences on antidepressant prescribing. Soc Sci Med 2003, 56:1335-1344.

68. Mort JR, Aparasu RR: Prescribing potentially inappropriate psychotropic medications to the ambulatory elderly. Arch Intern Med 2000, 160:2825-2831.

69. Briffault X, Morvan Y, Rouillon F, Dardennes R, Lamboy B: [Factors associated with treatment adequacy of major depressive episodes in France]. Encéphale 2010, 36(Suppl 2):D59-72.

70. Briffault X, Morvan Y, Rouillon F, Dardennes R, Lamboy B: [Use of services and treatment adequacy of major depressive episodes in France]. Encéphale 2010, 36(Suppl 2):D48-58,

71. Smith BH, Torrance N: Management of chronic pain in primary care. Curr Opin Support Palliat Care 2011, 5:137-142.

doi:10.1186/1471-2296-14-55

Cite this article as: Mercier et al: Evidence of prescription of antidepressants for non-psychiatric conditions in primary care: an analysis of guidelines and systematic reviews. BMC Family Practice 2013 14:55.

\section{Submit your next manuscript to BioMed Central and take full advantage of:}

- Convenient online submission

- Thorough peer review

- No space constraints or color figure charges

- Immediate publication on acceptance

- Inclusion in PubMed, CAS, Scopus and Google Scholar

- Research which is freely available for redistribution 